\title{
Unfair treatment and self-regulatory focus is
}

\author{
Daphna Oyserman *, Ayse K. Uskul, Nicholas Yoder, Randy M. Nesse, David R. Williams
}

The Institute for Social Research, The University of Michigan, 426 Thompson Ave., Ann Arbor, MI 48106-1248, USA

Received 27 January 2005; revised 22 February 2006

Available online 24 July 2006

\begin{abstract}
Ample correlational evidence exists that perceived unfair treatment is negatively related to well-being, health, and goal striving but the underlying process is unclear. We hypothesized that effects are due in part to contextual priming of prevention focus and the negative consequences of chronic prevention-focused vigilance. Indeed, reasonable responses to unfair treatment- to avoid situations in which it occurs or if this is not possible, confront it head on-fit prevention self-regulatory focus response patterns. Results from three experiments support this notion. Priming stigmatized social category membership heightened students' prevention (not promotion) focus $(n=117)$. Priming non-stigmatized social category membership (i.e., white) did not change prevention focus $(n=46)$. Priming prevention (not promotion) increased perceptions of unfair treatment (and aroused prevention-relevant fight or flight responses) in response to a negative ambiguous job situation among low and moderate income adults $(n=112)$.
\end{abstract}

(c) 2006 Elsevier Inc. All rights reserved.

Keywords: Unfair treatment; Self-regulatory focus; Prevention; Promotion; Discrimination; African American; Social class

Your professor asks if your parents ever went to college (they did not), your new supervisor hands you an unfavorable performance review (you are African American), leading you to wonder, 'is this fair; why is this happening to me?' In the current paper we explore situations like these and ask whether these kinds of contextual cues shift the attention of potentially stigmatized individuals to avoiding problems and the possible behavioral consequences of such shifts. We provide evidence for effects in both academic and workplace contexts.

Unfair treatment threatens self-concept by communicating a lack of regard for one's social identity and basic worth (Crocker, Major, \& Steele, 1998). It is psychologically dam-

\footnotetext{
Funding for this study was provided by a program project grant (Williams, Nesse, and Oyserman) funded within the African American Mental Health Research Program NIH Grant No. P01 MH58565 to James Jackson, by the Michigan Prevention Research Training Grant (NIH Grant No. T32 MH63057-03 to Oyserman), and a Canadian Social Science Research Council Postdoctoral Fellowship (to Uskul). We thank the interviewers and participants who took part in these studies.

* Corresponding author. Fax: +1 7346473652.

E-mail address: daphna.oyserman@umich.edu (D. Oyserman).
}

aging because it provides a sense of not mattering, and mattering, the feeling that others care about our fate and experience, is fundamental to well-being (Turner, Taylor, \& Gundy, 2004). Moreover, the experience of unfair treatment is derailing and disrupts pursuit of personal goals (Link, Cullen, Frank, \& Wonzniak, 1987). Examples include being excluded from fair chances at school or on the job (Pavalko, Mossakowski, \& Hamilton, 2003) or being the target of negative assumptions or poor service in public facilities (Neckerman, Carter, \& Lee, 1999). An essential characteristic of unfair treatment is the combination of negative outcomes and ambiguity that is both attributional (e.g., were the negative outcomes due to unfair treatment or were they due to my ability?) and behavioral (e.g., what is the appropriate response even if the treatment is unfair-should I ignore it, avoid this situation in the future, or confront the situation head on now?).

Perceived unfair treatment is associated with poor physical and psychological health and unfair treatment is more likely to be reported by members of stigmatized social groups. Increased chronic health problems (Guyll, Matthews, \& Bromberger, 2001), increased self-reported ill 
health (Gee, 2002; Schulz \& Israel et al., 2000a), increased psychological distress (Dion, Dion, \& Pak, 1992; Schulz \& Williams et al., 2000b), increased depression (Kessler, Mickelson, \& Williams, 1999), and lower life satisfaction (Schulz \& Williams et al., 2000b) have all been correlated with unfair treatment. African Americans are more likely to report unfair treatment than Whites (Schulz \& Williams et al., 2000b) and low-income African Americans are more likely to report unfair treatment than moderate income African Americans (Schulz \& Israel et al., 2000a).

Over time, members of stigmatized groups may become differentially sensitive to the possibility of unfair treatment (Mendoza-Denton, Downey, Purdie, Davis, \& Pietrzak, 2002; Pinel, 1999). This sensitivity has been studied as an individual difference variable in terms of stigma consciousness or the extent that individuals expect to be stereotyped (Pinel, 1999) and status-based rejection sensitivity or an anxious expectation of rejection based on group membership (Mendoza-Denton et al., 2002). Higher chronic expectation of unfair treatment increases likelihood both of perceived discrimination (whether rated as personal experience or likely in-group experience) and of withdrawal from situations that might involve competition with the outgroup (Pinel, 1999). Perhaps due to withdrawal from these situations, rejection sensitivity dampens likelihood of successful goal pursuit as operationalized as academic success in the first year of college (Mendoza-Denton et al., 2002).

In addition to individual differences in sensitivity to or anxious expectation of unfair treatment, some research also documents individual difference in redoubling of effort to succeed in the face of unfair treatment. Termed "John Henry-ism," (James, 1994), this response has been studied primarily among African Americans. It describes the extent to which individuals ignore unfair treatment and redouble effort to succeed in goal pursuit (e.g., the belief that hard work can overcome or help one get ahead). Those high in John-Henryism actively pursue goal achievement despite obstacles. They focus on larger goals such as academic or career goals, interpreting environmental feedback in terms of success in attaining goals or feedback suggesting the need to increase effort, ignoring the potential interpretation that discouraging feedback is based on social category rather than personal effort. Among women, John Henryism is associated with better health outcomes (Feldman \& Steptoe, 2003). Other researchers have termed this the 'strong Black woman' or 'strong Black man' syndrome, in which individuals endorse the notion that they can continue to pursue goals in spite of obstacles (Romero, 2000). Miller and Myers (1998) note a similar strategy among members of another stigmatized group, heavy weight women, who redoubled their efforts, becoming especially skilled in interacting with the non-heavy weight to minimize unfair treatment. Thus, individuals may focus on attaining positive outcomes and success in spite of unfair treatment by seeking out additional opportunities, putting in extra effort or trying another angle or vantage point.

Chronic individual differences in sensitivity to and response to unfair treatment highlight useful individual difference in the likelihood of cautiously avoiding situations in which unfair treatment may occur, even if avoiding the situation reduces likelihood of attaining important goals, and in the likelihood of focusing on attaining important goals in spite of unfair treatment. However, individual difference approaches do not take into account the importance of immediate social context in channeling responses (e.g., Carver \& Scheier, 1998; Higgins, 1998). Inhibition and activation self-regulatory system models (Gray, 1990) postulate a preattentive system that automatically screens the environment for threatening stimuli (Ohman, 1993). Prevention focus is cued when safety and security needs are made salient; promotion focus is cued when goal pursuit seems possible (Higgins, 1998). In his elaboration on this work, Larsen (2004) describes contextually primed differences in self-regulatory strategy, proposing that environmental cues set the course of ensuing information processing. Within this model, detecting threatening information tunes attention, perception, judgment, and memory toward outcomes relevant to threat.

Detecting a threat means that all is not well; one better proceed with care until assured that the threat is not serious. The automatic vigilance system accomplishes this by directing cognitive resources toward potentially threatening information (Larsen, 2004). Thus, threat does not freeze all action but rather redirects focus (and action) to harm reduction, with focus redeployed toward the initial goal only once the threat is resolved. We propose that situations that look dangerous will cue the vigilance system, heighten prevention focus, and thus prompt situation specific sensitivity to the possibility of unfair treatment. Following a self-regulatory focus model, when the potential for unfair treatment is primed it triggers prevention-focused self-regulation. Prevention-focus self-regulation should prompt scanning for unfair situations and cue avoiding or extricating oneself from the unfair situation if possible, and if avoiding or extricating strategies are not viable, prevention-focused safety concerns should prompt protecting oneself by confronting the instigator of unfair treatment. Subtle situational cues that turn on preventionfocused self-regulation can therefore also trigger focus on unfair treatment. In the current paper, we first explore the effect of making salient stigmatized group membership on the activation of prevention (vs. promotion) self-regulatory focus (Study 1), document that the effect of making group membership salient on activation of prevention focus occurs only when the primed in-group is a potentially stigmatized group (i.e., not white) (Study 2) and then explore the effect of priming self-regulatory focus on perception of and reported response to potential unfair treatment (Study 3).

\section{Study 1}

\section{Method}

\section{Participants}

Undergraduate students participated as part of their psychology course requirements $(n=59)$ or via e-mail solicitation for volunteers $(n=58)$. 


\section{Procedure}

The experiment was completed on-line without experimenter contact to reduce the possibility of extraneous variables influencing interpretation. To obtain participants who were members of stigmatized social groups, participants in the psychology subject pool were pre-screened for minority race/ethnicity, non-heterosexual sexual orientation, low socio-economic status (SES), mental health problems, and physical disability; relevant student interest groups were contacted via e-mail to supplement sample size. Participants first read the consent form, then clicked on a link which randomly assigned them to stigmatized social group membership salient $(n=56)$ or not salient condition $(n=61)$.

Identity salience was primed by having participants fill out the socio-demographic items prior to filling out the selfregulatory focus items.

\section{Measures}

Socio-demographics. Students were asked to indicate their gender ( $n=86$ female, $n=29$ male, $n=1$ transgender), race ( $n=74$ white, $n=40$ biracial or of color), sexual orientation ( $n=90$ heterosexual, $n=25$ gay, lesbian, or bisexual), physical ability ( $n=108$ physically able, $n=6$ students with a physical disability), SES [using a 5-point scale anchored at $1=\mathrm{a}$ lot better off than other University of Michigan students $(n=3)$ and $5=$ a lot less well off than other University of Michigan students $(n=34)$ ], and mental health $(n=51$ noted that they had a mental health problem and $n=63$ did not). In each case, students were allowed an option of choosing not to answer so responses do not sum to 117 .

Stigmatized social group membership. Following the coding scheme of Frable, Platt, and Hoey (1998), all participants were members of concealable-stigma (lesbian, gay, bisexual, low SES, mental disability) or conspicuous-stigma social groups (person of color, women, transgender, or physically disabled). The two forms of stigma overlapped highly in our sample, precluding separate analyses. Coding was done twice- once including, and once excluding individuals whose sole stigma was being female. Sample size shifts by 10 when these individuals are excluded. Since effects remain the same when the 10 women are excluded, analyses present results including women.

Self-regulatory focus. The Lockwood, Jordan, and Kunda (2002) 9-point Likert response scale $(1=$ not at all true for me to $9=$ very true for me) measures were used. Prevention (9-items, $M=5.86, S D=1.37, \alpha=.84$ ) and promotion (10items, $M=7.71, S D=.86, \alpha=.83)$ scores were orthogonal, $r=.10, n s$.

Unfair treatment. Unfair treatment (e.g., "How often are you treated with less respect than other people") was measured with the everyday discrimination scale a 9-item, 6point Likert scale $(1=$ almost everyday to $6=$ never $)$ (Wil- liams, Yu, Jackson, \& Anderson, 1997). On average, respondents reported experiencing unfair treatment at least once a week $(M=2.43, S D=.87, \alpha=.90)$. Because the unfair treatment scores were significantly positively skewed, a median split (cut at experiencing unfair treatment at least once a week) was used in analyses.

\section{Results and discussion}

To examine the hypothesized effect of environmental cues on prevention focus, analyses of variance was utilized to examine the effect of making stigmatized social group membership salient (vs. not salient) on prevention self-regulatory focus and promotion self-regulatory focus. As expected, prevention self-regulatory focus increased when one's stigmatized social group membership was primed $(M=6.16$, $S D=1.43)$ compared to when it was not $(M=5.60$, $S D=1.27), F(1,115)=5.85, p=.017$. However, no effect on promotion self-regulatory focus was found, $F(1,115)=.10$, $p=.75\left(M_{\text {salient }}=7.75, S D=.92 ; M_{\text {not salient }}=7.67, S D=.80\right)$.

A follow-up two-way ANOVA added potential interaction with experience of unfair treatment-recall that we predicted that situational priming of potential unfair treatment would cue prevention-focus independent of prior experience of unfair treatment. As predicted, the main effect of priming on prevention was not qualified by prior experience with unfair treatment, $F(1,113)=2.48, p=.24$. Primed stigmatized social group membership cued prevention focus, $F(1,113)=4.68, p=.03$, prior experience with unfair treatment did not, $F(1,113)=3.18, p=.19$. As before, no main $(F(1,113)=.28, p=.60)$ or moderating $(F<1)$ effects of priming stigmatized social group membership were found for promotion focus, nor was there a main effect of the experience with unfair treatment, $F(1,113)=1.04$, $p=.31$.

Study 1 results support the notion that cuing the potential for unfair treatment by making stigmatized social category membership salient primes prevention focus. To examine whether the effect of priming stigmatized in-group membership was indeed limited to members of stigmatized groups, in Study 2, we primed in-group membership among non-stigmatized individuals (i.e., white).

\section{Study 2}

\section{Method}

\section{Participants and procedure}

We replicated Study 1 procedures described above with a sample of students and non-students who indicated no stigmatized identity. Students $\left(n=28, M_{\text {age }}=18.61,13\right.$ men, 15 women) were recruited from the psychology subject pool by pre-screening for individuals who self-identified as White or European-American, heterosexual, belonging to middle or high SES, and who had no mental or physical disability. Non-students $\left(n=18, M_{\text {age }}=22.67,5\right.$ men, 13 women) who self-identified as White or European-Ameri- 
can, heterosexual, belonging to middle or high SES, and who had no mental or physical disability were recruited by posting the study on websites that announce on-line psychology studies (e.g., http://www.socialpsychology.org/ expts.htm).

Prevention $(M=5.45, S D=1.30, \alpha=.79)$ and promotion $(M=7.82, S D=.63, \alpha=.78)$ scores were orthogonal in both student $(r=-.005, p=.98)$ and non-student $(r=-.091$, $p=.72$ ) samples. The student sample did not differ from the non-student sample on either of the study variables; the two samples were combined for further analysis. On average, respondents reported experiencing unfair treatment less than a few times a year $(M=4.57, S D=.61, \alpha=.90)$.

\section{Results and discussion}

Following the analysis plan in Study 1, we first conducted an analysis of variance to examine the effect of making social group membership salient on prevention and promotion self-regulatory foci. Prevention self-regulatory focus did not increase when one's non-stigmatized social group membership was made salient $(M=5.59, S D=1.15)$ compared to when it was not $(M=5.33, S D=1.41)$, $F(1,44)=.45, p=.51$. Similarly, promotion scores did not differ as a function of the prime $F(1,44)=.19, p=.66$ $\left(M_{\text {salient }}=7.77, S D=.77 ; M_{\text {not salient }}=7.85, S D=.51\right)$. Findings did not change when female participants were excluded from the sample.

Adding experience with unfair treatment into the ANOVA showed that this variable was significantly associated with prevention self-regulatory focus in this non-stigmatized group, $F(1,42)=7.15, p=.011$, those reporting more frequent experience of unfair treatment scored higher on prevention $(M=5.88, S D=1.13)$ than those reporting less frequent experience with unfair treatment $(M=4.89$, $S D=1.32$ ). However, experience with unfair treatment did not modify effects the salience prime, $F<1, p=.91$. No effects were found for promotion focus; neither priming social group membership, $F<1, p=.70$; nor the interaction of the experience of unfair treatment and salience of group membership, $F<1, p=.41$ were significant. Experience with unfair treatment tended to be negatively associated with promotion scores, $F(1,42)=3.38, p=.073$, such that those who reported more frequent experience with unfair treatment scored lower on promotion $(M=7.68, S D=.66)$ compared to those that reported less frequent experience with unfair treatment $(M=8.00, S D=.55)$.

In Study 1, making stigmatized social category membership salient elicited prevention focus regardless of past experience with unfair treatment, in Study 2, making nonstigmatized social status did not elicit prevention focus. Making stigmatized category salient seems sufficient to produce vigilance, suggesting ubiquity of knowledge of the potential for unfair treatment in an academic setting. For individuals for whom social category membership is not stigmatizing, prior experience of unfair treatment is associated with chronic difference in regulatory focus. These find- ings are important given recent research suggesting that prevention focus is a mediating mechanism in performance decrement in stereotype threat situations (Seibt \& Förster, 2004). It is possible that part of the negative effect of prevention focus is that by cuing vigilance, it focuses attention on the potential for unfair treatment, prompting responses that fit the possibility, including fight or flight (withdrawal) responses, neither of which facilitate academic performance.

We begin to investigate these issues in Study 3. To increase the generalizability of findings, we turn from an academic situation to the work place and to a community sample of low to moderate income African American and European American adults. We examine the effect of priming prevention vs. promotion self-regulatory focus on interpretation and response in ambiguous work situations with negative outcomes. We hypothesize that priming prevention focus will make the potential for unfair treatment salient and prompt defensive flight or fight responses. We explore whether personal history with unfair treatment increases sensitivity to unfair treatment or if as in Studies 1 and 2 personal experience is not required because knowledge of the threat of unfair treatment is 'in the air' or common knowledge.

\section{Study 3}

\section{Method}

\section{Sample}

Adults ( $n=112 ; n=58$ African Americans, $n=54$ European Americans) aged 25-55 participated as part of the Ypsilanti Everyday Stress and Health (YES Health) study.

\section{Procedure}

Census block-groups (the smallest census defined geographic areas) were used to quota-sample four neighborhood types defined by race (white, black) and income (low, moderate). To obtain a race and gender balanced sample, equal numbers of men and women from the census-block dominant race were sampled from each neighborhood type. Neighborhood income was operationalized as median household income relative to the poverty line $(<150 \%$ vs. $250 \%$ ).

The study took place in a space provided by a community hospital, as part of a larger study focused on stress, health, and health history. Participants were randomly assigned to a promotion $(n=57)$ or prevention $(n=55)$ prime condition following Higgins' use of obligations and ought selves to prime prevention focus and use of ideal selves and aspirations to prime promotion focus (Higgins, Roney, Crowe, \& Hymes, 1994). To prime promotion, participants were asked to recall their own and their parents' ideals, hopes, and dreams for them as children, and their own hopes, dreams, and ideals now. For prevention, the probes focused on their parents' expectations for them when they were children and their duties and obligations 
now. Following the prime, participants were read an ambiguous scenario about a job in which equal numbers of positive and negative attributes were mentioned but the current situation was negative (negative supervisor rating) and asked what they thought was happening and how they would respond. The scenario was:

"You've been working at the same job a while. It's easy to get to, the schedule suits you, and it pays well. One thing that has changed though-you got a different supervisor. You just completed your annual evaluation and the new supervisor says you are slacking off, that you are not working hard enough, and that you are not consistently doing high-quality work. You got good evaluations from your old supervisor and you are surprised because you thought you WERE working hard and you don't even recall the new supervisor watching you. You wonder if someone has been saying negative things, or if he just thinks that you're somehow an inferior worker. You could get another job, but this is a good job."

Participants were then asked two open-ended questions: "What would you do?" and "What do you think the problem is?" Responses were taped, transcribed and contentcoded by two coders, blind to condition ( $86 \%$ agreement). Following Major, Quinton, and McCoy (2002) articulation of discrimination as situations external to the self in which other's unjust action results in negative outcomes, we coded interpretation of the problem for focus on the unfair situation vs. the self as the locus of the problem. Responses that fit neither of these categories (e.g., other blame with no unjust interpretations attached such as 'the supervisor was just trying to show off') $(12.5 \%)$ were not included in further analyses. Almost all participants provided a single categorizable response $(84.8 \%)$; therefore responses were coded for presence or absence of each category. Analyses were done twice - once including, and once excluding those participants who generated both an unfair situationfocused and self-focused interpretation $(n=10)$. Since effects remain the same when these individuals are excluded, analyses present results including those who generated both responses.

In addition, as a preliminary test of the impact of prevention focus on behavior, responses were also coded for responses aimed at the situation (quitting, confronting, going to the supervisor) and responses aimed at self-change (working to keep the job, trying harder) response. Responses that fit neither of these categories (e.g., 'I would do something, that's it.') $(12.5 \%)$ were not included in further analyses. Analyses were done twice-once including, and once excluding those participants who generated both situation-focused and self-focused action $(n=15)$. Effects were the same when these individuals are excluded, so analyses present results including all participants.

We also obtained chronic self-regulatory focus and past experience of unfair treatment. Priming and the chronic self-regulatory focus scale were presented in counterbalanced order, half of participants got the chronic scale prior to the prime and scenario and half after the prime and sce- nario. No order effect was found in any of the preliminary analyses. Therefore, order of presentation of chronic selfregulatory focus vs. primed self-regulatory focus and scenario is omitted as a variable in analyses. Experience of unfair treatment was always presented after the other variables. Over $97 \%$ of responses were in the first person, suggesting personal engagement in the scenario.

\section{Measures}

Self-regulatory focus. Higgins' (Higgins et al., 2001) 5-item prevention $(M=2.99, S D=.85, \alpha=.76)$ and 6-item promotion $(M=3.59, S D=.55, \alpha=.60)$ scales were used, scale scores were orthogonal, $r=-.03$, ns. The scales are anchored at $1=$ never to $5=$ very often or $1=$ certainly false to $5=$ very true.

Unfair treatment. The full everyday discrimination scale (Williams et al., 1997), a 9-item, 6-point Likert scale ( $1=$ almost everyday to $6=$ never), $M=2.38, S D=.92$, $\alpha=.85$, was used to assess unfair treatment as in Studies 1 and 2. Respondents on average reported experiencing unfair treatment at about at least once a week.

\section{Results and discussion}

Logistic regression equations were used to predict our four dichotomous outcome variables (did/did not generate an interpretation focused on the situation as unfair, one's self or need for personal change; did/did not generate an action response focused on getting out of the situation, self-effort). Sample size did not allow for simultaneous entry of demographic and personal history variables so we conducted two sets of logistic regressions for each outcome variable. In the first set, the regulatory focus prime was entered in block 1, the categorical demographic variables in block 2 , and the relevant interaction terms in block 3. In the second set the regulatory focus prime was entered in block 1, the continuous personal history variables (chronic self-regulatory focus, past experience of unfair treatment) in block 2, and the relevant interaction terms in block 3 .

At block 1, prime significantly predicted perception of unfair treatment (e.g., supervisor discriminates based on my appearance), $\chi^{2}(1, n=112)=6.27, p=.01(B=.97, S E=.39$, $p=.01)$ and generation of situation-focused action (e.g., I had leave, quit the job), $\chi^{2}(1, n=112)=3.72, p=.05$ $(B=.77, S E=.41, p=.05)$. The odds of perceiving unfair treatment were 2.63 times higher in the prevention prime condition than in the promotion prime condition and the odds of generating situation-focused action were 2.17 times higher in the prevention prime condition than in the promotion-prime condition. The addition of either the sociodemographic or the personal history variables (and relevant interaction terms) in blocks 2 and 3, respectively, did not significantly contribute to the prediction of the outcome variable in either regression equation. Neither the prime, nor any other predictor entered in the model signifi- 
cantly predicted self-focused interpretation and generation of self-focused action.

Auxiliary chi-square analyses revealed that, across participants and primes, generating self-focused action was associated with perceiving oneself to be part of the problem, $\chi^{2}=7.19, p=.007$, and generating situation-focused action was associated with perceiving unfair treatment as the problem, $\chi^{2}=4.36, p=.03$.

Priming prevention focus increased vigilance, resulting in interpreting a negative ambiguous situation as involving unfair treatment and therefore propensity to take action in accordance with this interpretation, such as quitting the job or as confronting the supervisor. No effects of the assessed socio-demographic variables (race, gender, SES) or the personal history variables (chronic self-regulatory focus and prior experience with unfair treatment) were found, suggesting that effects are situational, not person-driven (or confounded by individual differences). No effect of promotion-priming was found. A number of possible reasons for this null effect are equally plausible. The kinds of 'strong-person' or 'John Henry' responses found in the literature may indeed be an individual difference variables rather than a situationally cued response to potential unfair treatment. Alternatively, our promotion prime may have been insufficient because priming (to overcome rather than focus on unfair treatment) may involve a more specific 'take action' orientation toward the particular goal (e.g., academics, job performance). Third, priming for promotion may need to focus attention on social identity (e.g., 'we can handle this') rather than on personal competence to the extent that a 'John Henry' response is rooted in a social identity.

\section{General discussion}

Unfair treatment has important negative consequences but the field has just begun to consider the process by which negative effects unfold. The present research focused on understanding perception of and responses to unfair treatment. We focused on self-regulatory focus because self-regulatory systems have both psychological and physiological counterparts and provide an important link between goals and behavior (e.g., Carver \& Scheier, 1998; Gray, 1990; Idson \& Higgins, 2000).

The literature on unfair and discriminatory treatment suggests that common responses are to retreat from or avoid situations in which it might occur (e.g., Pinel, 1999) or to confront perpetrators (Swim \& Hyers, 1999). These responses fit a self-regulatory focus on prevention (e.g., Higgins et al., 2001). However, responses can also involve redoubling effort to attain goals in spite of discrimination or unfair treatment (James, 1994). These responses fit a self-regulatory focus on promotion (Oyserman \& Swim, 2001). We argued that priming social cues that highlight the potential for unfair treatment would increase prevention focus and that priming a prevention focus would increase sensitivity to unfair treatment and preference for situation-focused action. In Studies 1 and 2 we showed that making salient stigmatized (but not unstigmatized) social group membership increases prevention focus. This finding is consistent with research linking avoidant behaviors with concern about the potential for unfair treatment (e.g., Pinel, 1999) and research showing enhanced memory avoidance (compared to approach) behavior when stereotypes about one's in-group are primed (Seibt \& Förster, 2004). In Study 3, we showed that priming prevention focus increases sensitivity to cues of unfair treatment and situation-focused responding such as withdrawing from the situation, a finding consistent with research showing that prevention focus is associated with vigilance-related tactics (Higgins et al., 2001; Idson \& Higgins, 2000). Priming promotion focus did not influence the sense made of the situation or behavioral response in spite of the literature on John Henryism which would lead to the prediction that promotion priming would reduce salience of unfair treatment as an interpretation and increase focus on personal effort. It is possible that promotion focus is overridden when vigilance is required (e.g., Larsen, 2004). Thus, there some evidence that behavioral inhibition systems are more easily observed than behavioral activation systems when the possibility of losing something dominates (Avila, 2001). Our work scenario may have highlighted the possibility of loss rather than gain.

Taken together, the results from Studies 1-3 suggest that making stigmatized group membership salient turns on prevention focus and that prevention focus influences response. Once one believes unfair treatment has occurred on the job, one may feel forced to leave or take a principled stand. But neither of these may be stress-free in their consequences. Moreover, a number of studies suggest that prevention orientation (as compared with promotion orientation) has performance costs. It is associated with worse performance on creativity tasks, generation of fewer hypotheses, less inclusive use of categories, and perseverance on initial response rather than testing alternatives (e.g., Crowe \& Higgins, 1997; Seibt \& Förster, 2004), all of which suggest that priming prevention focus may be stressing and debilitating. Our results also resonate with stereotype threat (Steele, 1997) research showing decreased performance when stigmatized category membership is primed. Effects are hypothesized as due to an apprehension about confirming stereotypes about one's in-group in situations in which the stereotype is salient and self-relevant. Although, we did not focus on performance per se, the current findings suggest that making salient stigmatized category membership activates prevention focus and prevention focus increases focus on possible unfair treatment with concurrent attention to how to get out of the situation, all of which drains attention from engaging in the goal at hand.

Future research is needed to test the possible mediating role of prevention-focused self-regulation on the relation- 
ship between unfair treatment and negative physical and psychological health consequences and the potential of promotion strategies to buffer these negative effects. Initial and indirect evidence suggests that prevention strategies coupled with an unfair situation undermines psychological well-being: Eiser, Eiser, and Greco (2004) showed that parental use of prevention-focused strategies in coping with a cancer-survivor child predicted dampened well-being for both parent and child. Ayduk, May, Downey, and Higgins (2003) showed that preventionfocused and rejection sensitive individuals were prone to use covert strategies to cope with rejection. Covert coping is associated with high blood pressure (Theorell, Alfredsson, Westerholm, \& Falck, 2000) and signs of coronary heart disease (Harenstam, Theorell, \& Kaijser, 2000). However, it is also possible that prevention focus can have positive consequences of appropriately alerting individuals to the potential for danger and appropriately turning on "take care" responses. Understanding how self-regulatory focus may alleviate or exacerbate negative effects of unfair treatment is an important goal.

\section{References}

Avila, C. (2001). Distinguishing BIS-mediated and BAS-mediated disinhibition mechanisms: a comparison of disinhibition models of Gray (1981, 1987) and of Patterson and Newman (1993). Journal of Personality and Social Psychology, 80, 311-324.

Ayduk, O., May, D., Downey, G., \& Higgins, E. T. (2003). Tactical differences in coping with rejection sensitivity: the role of prevention pride. Personality and Social Psychology Bulletin, 29, 435-448.

Carver, C. S., \& Scheier, M. F. (1998). On the self-regulation of behavior. New York: Cambridge University Press.

Crocker, J., Major, B., \& Steele, C. (1998). Social stigma. In D. T. Gilbert \& S. T. Fiske (Eds.), Handbook of social psychology (Vol. 2, fourth ed., pp. 504-553). New York: McGraw-Hill.

Crowe, E., \& Higgins, E. T. (1997). Regulatory focus and strategic inclinations: promotion and prevention in decision-making. Organizational Behavior and Human Decision Processes, 69, 117-132.

Dion, K. L., Dion, K. K., \& Pak, A. W. (1992). Personality-based hardiness as a buffer for discrimination-related stress in members of Toronto's Chinese community. Canadian Journal of Behavioral Science, 24, 517-536.

Eiser, C., Eiser, J. R., \& Greco, V. (2004). Surviving childhood cancer: quality of life and parental regulatory focus. Personality and Social Psychology Bulletin, 30, 123-133.

Feldman, P. J., \& Steptoe, A. (2003). Psychosocial and socioeconomic factors associated with glycated hemoglobin in nondiabetic middle-aged men and women. Health Psychology, 22, 398-405.

Frable, D. E. S., Platt, L., \& Hoey, S. (1998). Concealable stigmas and positive self perceptions: feeling better around similar others. Journal of Personality and Social Psychology, 74, 909-922.

Gee, G. C. (2002). A multilevel analysis of the relationship between institutional and individual racial discrimination and health status. American Journal of Public Health, 92, 615-623.

Gray, J. A. (1990). Brain systems that mediate both emotion and cognition. Cognition \& Emotion, 4, 269-288.

Guyll, M., Matthews, K. A., \& Bromberger, J. T. (2001). Discrimination and unfair treatment: relationship to cardiovascular reactivity among African American and European American women. Health Psychology, 20, 315-325.

Harenstam, A., Theorell, T., \& Kaijser, L. (2000). Coping with anger-provoking situations, psychosocial working conditions, and ECG-detected signs of coronary heart disease. Journal of Occupational Health Psychology, 5, 191-203.

Higgins, E. T. (1998). Promotion and prevention: regulatory focus as a motivational principle. Advances in Experimental Social Psychology, $30,1-46$.

Higgins, E. T., Friedman, R. S., Harlow, R. E., Idson, L. C., Ayduk, O. N., \& Taylor, A. (2001). Achievement orientation from subjective histories of success: promotion pride versus prevention pride. European Journal of Social Psychology, 31, 3-23.

Higgins, E. T., Roney, C. J. R., Crowe, E., \& Hymes, C. (1994). Ideal versus ought predilections for approach and avoidance distinct self-regulatory systems. Journal of Personality and Social Psychology, 66, 276-286.

Idson, L. C., \& Higgins, E. T. (2000). How current feedback and chronic effectiveness influence motivation: everything to gain versus everything to lose. European Journal of Social Psychology, 30, 583-592.

James, S. A. (1994). John Henryism and the Health of African Americans. Culture, Medicine, and Psychiatry, 18, 163-182.

Kessler, R. C., Mickelson, K. D., \& Williams, D. R. (1999). The prevalence, distribution, and mental health correlates of perceived discrimination in the United States. Journal of Health and Social Behavior, 40, 208-230.

Larsen, R. L. (2004). Emotion and cognition: the case of automatic vigilance. Psychological Science Agenda (APA Online), 18.

Link, B. G., Cullen, F. T., Frank, J., \& Wonzniak, J. F. (1987). The social rejection of ex-mental patients: understanding why labels matter. American Journal of Sociology, 92, 1461-1500.

Lockwood, P., Jordan, C., \& Kunda, Z. (2002). Motivation by positive or negative role models: regulatory focus determines who will best inspire us. Journal of Personality and Social Psychology, 83, 854-864.

Major, B., Quinton, W. J., \& McCoy, S. K. (2002). Antecedents and consequences of attributions to discrimination: theoretical and empirical advances. Advances in Experimental Social Psychology, 34, 251-320.

Mendoza-Denton, R., Downey, G., Purdie, V. J., Davis, A., \& Pietrzak, J. (2002). Sensitivity to status-based rejection: implications for African American students' college experience. Journal of Personality and Social Psychology, 83, 896-918.

Miller, C. T., \& Myers, A. M. (1998). Compensating for prejudice: How heavyweight people (and others) control outcomes despite prejudice. In J. K. Swim \& C. Stangor (Eds.), Prejudice: The target's perspective (pp. 191-218). New York: Academic Press.

Neckerman, K. M., Carter, P., \& Lee, J. (1999). Segmented assimilation and minority cultures of mobility. Ethnic and Racial Studies, 22, 945-965.

Ohman, A. (1993). Fear and anxiety as emotional phenomena: Clinical phenomenology, evolutionary perspectives, and information processing mechanisms. In M. Lewis \& J. M. Haviland (Eds.), Handbook of emotions (pp. 511-536). New York: Guilford Press.

Oyserman, D., \& Swim, J. (2001). Stigma: an insider's view. Journal of Social Issues, 57, 1-14.

Pavalko, E. K., Mossakowski, K. N., \& Hamilton, V. J. (2003). Does perceived discrimination affect health? Longitudinal relationships between work discrimination and women's physical and emotional health. Journal of Health and Social Behavior, 44, 18-33.

Pinel, E. C. (1999). Stigma consciousness: the psychological legacy of social stereotypes. Journal of Personality and Social Psychology, 76, $114-128$.

Romero, R. E. (2000). The icon of the strong black woman. In L. C. Jackson \& B. Greene (Eds.), Psychotherapy with African American women: Innovations in psychodynamic perspectives and practice (pp. 225-238). New York: Guilford Press.

Schulz, A., Israel, B., Williams, D., Parker, E., Becker, A., \& James, S. (2000a). Social inequalities, stressors and self reported health status among African American and White women in the Detroit metropolitan area. Social Science and Medicine, 51, 1639-1653.

Schulz, A., Williams, D., Israel, B., Becker, A., Parker, E., James, S. A., et al. (2000b). Unfair treatment, neighborhood effects, and mental health in 
the Detroit metropolitan area. Journal of Health and Social Behavior, $41,314-332$.

Seibt, B., \& Förster, J. (2004). Stereotype threat and performance: how self-stereotypes influences processing by inducing regulatory foci. Journal of Personality and Social Psychology, 87, 38-56.

Steele, C. M. (1997). Race and the schooling of Black Americans. In L. A. Peplau \& S. E. Taylor (Eds.), Sociocultural perspectives in social psychology: Current readings (pp. 359-371). Englewood Cliffs, NJ: Prentice-Hall.

Swim, J. K., \& Hyers, L. L. (1999). Excuse me, what did you say? Women's public and private responses to sexist remarks. Journal of Experimental Social Psychology, 35, 68-88.
Theorell, T., Alfredsson, L., Westerholm, P., \& Falck, B. (2000). Coping with unfair treatment at work-what is the relationship between coping and hypertension in middle-aged men and Women? An epidemiological study of working men and women in Stockholm (the WOLF study). Psychotherapy and Psychosomatics, 69, 86-94.

Turner, R. J., Taylor, J., \& Gundy, K. V. (2004). Personal resources and depression in the transition to adulthood: ethnic comparisons. Journal of Health and Social Behavior, 45, 34-53.

Williams, D. R., Yu, Y., Jackson, J., \& Anderson, N. (1997). Racial differences in physical and mental health: socioeconomic status, stress, and discrimination. Journal of Health Psychology, 2, 335-351. 